\title{
BRONCHIAL ASTHMA AND CHLAMYDIA PNEUMONIAE ANTIBODIES IN CHILDREN AGED 4-8 YEARS IN OLOMOUC DISTRICT
}

\author{
František Kopřivaa , Jaroslava Szotkowskáb, Martin Zápalka
}

\author{
${ }^{a}$ Department of Pediatrics, Faculty of Medicine, Palacky University, 77506 Olomouc, Czech Republic \\ ${ }^{b}$ Department of Immunology, Faclulty of Medicine, Palacky University \\ e-mail:Koprivaf@fnol.cz
}

Received: October 3, 2005; Accepted (with revisions): November 14, 2005

Key words: Chlamydia pneumoniae/Bronchial asthma/Cough/Children/Atopic/Non-atopic

BACKGROUND. Although several studies have demonstrated an association between infection with Chlamydia pneumoniae and asthma, these were mainly limited to exacerbation of symptoms in adults with known asthma

OBJECTIVE. We investigated the role of C. pneumoniae infection in 149 atopic children with chronic cough and asthma, comparing them with 241 control non-atopic subjects presenting at Olomouc hospital between 1999 and 2003 with non-specific symptoms (temperature above normal (subfebrile), abdominal pain, arthralgia, and other symptoms.

METHODS. The levels of C. pneumoniae-specific antibodies were measured using Chlamydien-rELISA kits (Medac, Hamburg, Germany).

RESULTS. In a group of 83 atopic children with chronic cough, IgM and IgG antibodies to C. pneumoniae were demonstrated in 20 children ( $24 \%$ ). Among children with bronchial asthma, positive antibody was present in 29 children (44 \%; /p =0,052/); of this number, 24 (36\%; /p =0,06/) had IgM and IgG antibodies while 5 children ( $8 \%)$ had $\mathrm{IgA}$ and $\mathrm{IgG}$ antibodies against C. pneumoniae. A group of non-atopic children with non-specific symptoms included 38 children (16\%) with antibody positivity; 27 children (11\%) with IgM and IgG antibodies and 11 children (5\%) with IgA and IgG antibodies against C. pneumoniae.

CONCLUSIONS. Asthma in children was associated with elevated levels of IgM and IgG antibodies to C. pneumoniae.

\section{INTRODUCTION}

Chlamydia pneumoniae is common intracellular respiratory pathogen, and although many infections are believed to be asymptomatic, a growing body of evidence suggests an association between C. pneumoniae infection and asthma in some individuals ${ }^{1}$. For the clinician, the diagnosis of C. pneumoniae infection may be difficult because of the lack of widespread availability of diagnostic facilities for either organism identification or serologic testing, and because of controversies surrounding serodiagnostic criteria. The association was first described by
Hahn et al., who reported wheezing in 9 out of 19 adult patients with serologic evidence of current or recent C. pneumoniae infection ${ }^{2}$. In another study $11 \%$ asthmatic and $5 \%$ control children found to have positive cultures for C. pneumoniae ${ }^{3}$. Although some results were controversial, several studies confirmed these findings $s^{4,5,6}$. Our study aimed to investigate the current situation in the seroprevalence of C. pneumoniae infection in Olomouc district in a group of atopic children with chronic cough and asthma compared with a control group of non-atopic children with non-specific symptoms, i.e., temperature above normal, abdominal pain, arthralgia, fatigue.

Table 1. Characteristics of atopic a non-atopic children $(n=390$, median 5 years $)$

\begin{tabular}{|c|c|c|c|c|}
\hline & \multicolumn{3}{|c|}{ Atopic children } & Non-atopic children \\
\hline & & Cough & Bronchial asthma & \\
\hline Boys & 88 & 49 & 35 & 170 \\
\hline Girls & 61 & 34 & 31 & 71 \\
\hline $\mathrm{n}$ & 149 & 83 & 66 & 241 \\
\hline
\end{tabular}

Non - atopic patients with subfebrile, abdominal pain, arthralgia, fatigue 


\section{MATERIALS AND METHODS}

We conducted a retrospective study including 390 children ( 258 boys and 132 girls) aged 4-8 years (median, 5 years) examined in a pediatric outpatient unit and hospitalized in the Department of Pediatrics of Palacky University School of Medicine and University Hospital in Olomouc (Czech Republic) 1999-2003 period (Table 1). Each child had a detailed history taken and total serum immunoglobulin E (S-IgE) levels determined. Atopic children had a positive skin test (wheal $\geq 3 \mathrm{~mm}$ ) to at least one of the most common aeroallergens from our area (house-dust-mites, grass pollen, birch pollen, cat and dog danger, and mold mixture). Ineligible for the study were children with congenital respiratory tract anomalies and those with a serious respiratory disease, e.g., cystic fibrosis.

A total of 149 atopic children ( 88 boys and 61 girls): ${ }^{1}$ 83 children $(55.7 \%)$ referred for examination with nonproductive chronic cough, predominantly night-time cough persisting for more than three weeks; ${ }^{2} 66$ pediatric patients (44.3\%) with persistent mild bronchial asthma (according to GINA 2002), had levels of antibody against C. pneumoniae determined using ELISA and ChlamydienrELISA kits (Medac, Hamburg, Germany) ${ }^{7}$.

S-IgE levels were determined by nephelometry. S-IgE values of $150 \mathrm{IU} / \mathrm{ml}$, determined in our laboratory, are considered a significant marker of allergy. All atopic children had total S-IgE levels higher than $150 \mathrm{IU} / \mathrm{ml}$.
The same investigations were undertaken in a control group of non-atopic 241 (170 boys and 71 girls) children with subfebrile, abdominal pain, arthralgia, fatigue. None of these control children showed S-IgE levels over $150 \mathrm{IU} / \mathrm{ml}$.

Our data were analyzed statistically using contingence table and $\chi$ square test.

\section{RESULTS}

Among our 149 atopic children with chronic cough, 20 (24\%) with chronic cough were shown to have IgM and $\operatorname{IgG}$ antibodies against C. pneumoniae. Among children with bronchial asthma, positive antibodies were present in 29 children $(44 \% ; / p=0,052 /)$; of this number 24 children $(36 \% ; / p=0,06 /)$ had IgM and IgG antibodies while 5 children ( $8 \%$ ) had $\operatorname{IgA}$ and $\operatorname{IgG}$ antibodies against C. pneumoniae (Table 2, 3).

In the group of 241 non-atopic children with nonspecific symptoms, positive antibodies were found in 38 children (16\%), i.e. 27 children (11\%) with IgM and IgG antibodies and 11 children (5\%) with IgA and IgG antibodies against $\mathrm{C}$. pneumoniae.

Table 2. Number of examined children with chronic cough, bronchial asthma, non-specific symptoms and proportion of positive anti-Chlamydia $\mathrm{Ab}$

\begin{tabular}{|c|c|c|c|}
\hline & $\begin{array}{c}\text { Total/number } \\
\text { of positive Ab }\end{array}$ & \% of positive Ab \\
\hline Chronic cough & $83 / 20$ & 24 & 0,639 \\
\hline Bronchial asthma & $66 / 29$ & 44 & 0,052 \\
\hline $\begin{array}{c}\text { Non-specific symptoms, } \\
\text { non-atopic patients }\end{array}$ & $241 / 38$ & 16 & \\
\hline
\end{tabular}

$\mathrm{Ab}$ - antibody

Non - atopic patients with subfebrile, abdominal pain, arthralgia, fatigue

Table 3. Number of children with positive anti-Chlamydia $\mathrm{Ab}$ in individual groups

\begin{tabular}{|l|c|c|c|c|}
\hline & $\operatorname{IgM}+\operatorname{IgG}$ & $\operatorname{IgA}+\operatorname{IgG}$ & $\begin{array}{c}\operatorname{IgM}+\operatorname{IgG} \\
\operatorname{IgA}+\operatorname{IgG}\end{array}$ & $\mathrm{p}$ \\
\hline Chronic cough & $20(24 \%)$ & 0 & $20(24 \%)$ & 0.68 \\
\hline Bronchial asthma & $24(36 \%)$ & $5(8 \%)$ & $29(44 \%)$ & 0.06 \\
\hline $\begin{array}{l}\text { Non-specific symptoms, non-at- } \\
\text { opic patients }\end{array}$ & $27(11 \%)$ & $11(5 \%)$ & $38(16 \%)$ & \\
\hline
\end{tabular}

Non - atopic patients with subfebrile, abdominal pain, arthralgia, fatigue 


\section{DISCUSSION}

Chlamydia pneumoniae is a ubiquitous Gram-negative bacterium, an obligate intracellular parasite with a unique developmental cycle, and a common respiratory pathogen in children as well as adults ${ }^{8}$. Many infections are believed to be asymptomatic. Wheezing and cough are common features of chlamydial lung infections. The mechanism of this apparent association between C. pneumoniae infection and asthma is not clear, but presumably relates to chronic bronchial inflammation. Increased production of IL-1, IL-6, TNF- $\alpha$ and granulocyte macrophage-colony stimulating factor(GM-CSF) has been demonstrated in bronchial epithelial cells infected with C. pneumoniae. Inflammation in the airways in asthmatics is associated with healing processes resulting in scar formation and tissue remodeling, which seems to be present in almost all asthmatics whatever the severity, duration, or etiology of the asthma. C. pneumoniae may be one contributory factor in the development of irreversible changes in the airways. It has been suggested that bronchial hyper-reactivity may be caused by anti-C. pneumoniae IgE antibodies (implying allergic sensitization) ${ }^{9}$.

Our study supports the association between C. pneumoniae infection and asthma in children. One possible explanation is the finding of an association between variants of the alleles for mannose-binding lectin responsible for the increased incidence of $C$. pneumoniae infection in asthmatic children ${ }^{10}$. Cook et al. found that elevated levels of $\mathrm{IgG}$ antibody to $\mathrm{C}$. pneumoniae were significantly associated with severe chronic asthma and this association was not modified by potential confounding factors ${ }^{11}$. The presence of short-lived IgA antibodies has been proposed to indicate chronic infection or reinfection, whereas stable elevated levels of more long-lived IgG antibodies may reflect suffer infection in the past or chronic infection. The study by Black et al. showed an association of the severity of asthma and the mean IgG and IgA titers with C. pneumoniae infection ${ }^{12}$. Results of our study indirectly confirm the conclusions drawn in the above papers. A new diagnostic option is polymerase chain reaction (PCR).

If these associations are important, can we identify individuals at risk for asthma? The answer is: possibly, in the future. To survive within a macrophage, chlamydiae must not elicit a TH1-type CD4 lymphocyte response, such as would be promoted by interferon- $\gamma \cdot{ }^{13}$ Individuals with particular HLA class II genotypes might therefore be at a higher risk of chronic C. pneumoniae-associated disease $^{14}$.

Persistent or recurrent $C$. pneumoniae may both initiate the inflammatory process in some individuals, and amplify the inflammation in patients with early mild asthma leading to permanent changes in the airways and chronic disease. Macrolides are antibiotics with both antimicrobic and antiinflammatory activities and thus their use in asthmatic patients could lead to reduction of the airways inflammation and therefore improvement of symptoms and pulmonary function. Further studies are needed to examine the role of macrolides in asthma therapy. C. pneumoniae may persist in the lung after treatment ${ }^{15}$.

An association does not mean causality and it is possible that C. pneumoniae is coincidental in the bronchi of asthmatic children without playing a contributory role in the amplification of inflammation and progression of asthma.

We conclude that asthma in children was associated with elevated levels of IgM and IgG antibodies to C. pneumoniae. Our results are consistent with the hypothesis that C. pneumoniae infection may be involved in the development of asthma.

\section{REFERENCES}

1. Lemanske RF Jr.(2003) Is asthma an infectious diseasae? Thomas A Neff lecture. Chest $123,385 \mathrm{~S}-390 \mathrm{~S}$

2. Hahn DL, Dodge RW, Golubjatnikov R. (1991) Association of C. pneumoniae (strain TWAR) infection with wheezing, asthmatic bronchitis and adult-onset asthma. JAMA 266, 225-230

3. Emre U, Robin PM, Gelling M, Dumornay W, Rao M, Hammerschlag MR, et al. (1994) The association of Chlamydia pneumoniae infection and reactive airway disease in children. Arch Pediatr Adolesc Med 148, 727-732

4. Johnston SL.(2001) Is Chlamydia pneumoniae importance in asthma? The first controlled trial of therapy leaves the question unanswered. Am J Respir Crit Care Med 164: 513-514

5. Wark PA, Johnston SL, Simpson JL, Hensley MJ, Gibbon PG. (2002) Chlamydia pneumoniae immunoglobulin A reactivation and airway inflammation in acute asthma. Eur Respir J 20, 834840

6. Gencay M, Rudiger JJ, Tamm M, Soler M, Peruchoud AP, Roth M. (2001) Increased frequency of Chlamydia pneumoniae antibodies in patients with asthma. Am J Respir Crit Care Med 2001 163, 1097-1100

7. Hejnar P, Koukalova D. (2002) Serodiagnostics of chlamydial infections-significance of positivity in IgA and/or IgM antibody classes only. Biomed Pap Med Fac Univ Palacky Olomouc Czech Republic 46, 33-35

8. Cook PJ, Honeybourne D. (1994) Chlamydia pneumoniae. J Antimicrob Chemother 34, 859-873

9. Emre U, Sokolovskaya N, Robin PM, Schachter J, Hammerschlag MR. (1995) Detection of anti-Chlamydia pneumoniae IgE in children with reactive airway disease. J Infect Dis 172, 265-267

10. Nagy A, Kozma GT, Keszei M, Treszl A, Falus A, Szalai C. (2003) The development of asthma in children infected with Chlamydia pneumoniae is dependent on the modifying effect of mannose-binding lectin. J Allergy Clin Immunol 112, 729-734

11. Cook PJ, Davies W, Tunniclife W, Ayres JG, Honeybourne D, Wise R. (1998) Chlamydia pneumoniae and asthma. Thorax 53, 254-259

12. Black PN, Scicchitano R, Jenkins CR et al. (2000) Serological evidence of infection with Chlamydia. pneumoniae is related to the severity of asthma. Eur Respir J 15, 254-259

13. Dahlen GH, Boman J, Slunga L, Girgander LS, Lindblom B. (1995) $\mathrm{Lp}$ (a) lipoprotein, IgG, IgA and IgM antibodies to Chlamydia pneumoniae and HLA class II genotype in early coronary artery disease. Atherosclerosis 114, 165-174

14. Cook PJ. (1999) Antimicrobial therapy for Chlamydia pneumoniae: its potential role atherosclerosis and asthma. $\mathbf{J}$ Antimicrob Chemother 44, 145-148

15. Richeldi L, Ferrara G, Fabbri L, Lasserson T, Gibson P, Richeldi L. (2005) Macrolides for chronic asthma. Cochrane Database Syst Rev. 19,4:CD002997 